\title{
Socio-demographic and psychological aspects of children with thalassaemia
}

\author{
M I Rifaya ${ }^{1}$, S K Rajapaksa ${ }^{2}$, G L D C Prematilaka ${ }^{3}$, Nimanthika Hettiarachchi ${ }^{3}$
}

Sri Lanka Journal of Child Health, 2011; 40: 16-17

(Keywords: Thalassaemia; socio-demographic aspects)

\begin{abstract}
Objective To identify the socio-demographic and psychological aspects of thalassaemia

Method An observational descriptive study was carried out on 50 thalassaemic children, admitted for monthly blood transfusion to paediatric units of Teaching Hospital Kandy. Information was gathered using questionnaires.
\end{abstract}

Results Eighty four percent of the respondents were mothers. Age groups of children were: 1-4years (14\%), 5-9years (34\%), 10-14years $(36 \%)$, and 15 $20 y e a r s(16 \%)$. Sixty two percent were girls and $74 \%$ from the Central Province. Forty two percent were on subcutaneous desferrioxamine chelation, $8 \%$ on oral deferiprone and $50 \%$ on combined therapy. Thirty eight percent of children over ten years of age could self administer subcutaneous desferrioxamine. Eighty eight percent of parents had adequate knowledge about thalassaemia. In $88 \%$ father was the breadwinner. All said that they could not afford the expenses on travelling and investigations. Seventy five percent had satisfactory relationships with siblings and peers. In $74 \%$ teachers were happy about the school performance. Eighty six percent had family support but none had adequate social support.

Conclusions Eighty six percent had family support but none had adequate social support. Seventy five percent had satisfactory relationships with siblings and peers.

\section{Background}

Thalassaemia, like other chronic diseases, has important social and psychological implications ${ }^{1}$. The

${ }^{1}$ Senior Registrar in Paediatrics, ${ }^{2}$ Consultant
Paediatrician, ${ }^{3}$ Intern Medical Officer, Teaching
Hospital, Kandy

(Received on 6 January 2010. Accepted on 19 February 2010) way in which the family and patients come to terms with the disease and its treatment will have a critical effect on patient survival and quality of life ${ }^{1}$. Its frequent and complex treatment might lead to financial burden for the individual and his/her family ${ }^{2}$.

\section{Objective}

To identify the socio-demographic and psychological aspects of thalassaemia

\section{Method}

An observational descriptive study was carried out from November 2007 to January 2008 on 50 thalassaemic children admitted for monthly blood transfusion to paediatric units of Teaching Hospital Kandy. Information was gathered on demographic data, treatment modality, complications of the disease, care giver - patient relationship, parental knowledge about the disease, financial and social support. Questionnaires were completed by one of the investigators.

\section{Results}

Out of 50 respondents 42 (84\%) were mothers. Age groups of children were: 1 -4years $(14 \%)$, 5-9years (34\%), 10-14years (36\%), and 15-20years $(16 \%)$. Sixty two percent were girls. Thirty seven (74\%) were from the Central Province (34 from Kandy district). Seventy four percent of children were attending school (42\% primary, 32\% secondary), $16 \%$ were preschoolers and $10 \%$ had dropped out of school. Seventy two percent of caregivers studied above GCE ordinary level. Majority (86\%) of the children were Sinhalese. Forty two percent were on subcutaneous desferrioxamine chelation, $8 \%$ on oral deferiprone and $50 \%$ on combined therapy. Sixty six percent of parents felt that children were comfortable during their hospital stay. All were satisfied with the doctor-patient and nurse-patient communication regarding management, support and guidance. All $(100 \%)$ said that they get adequate supply of 
chelation therapy but the compliance was poor in $20 \%$. Ninety eight percent of parents were happy with the current treatment modality. Thirty eight percent of children over ten years of age could self administer subcutaneous desferrioxamine. Eighty eight percent of parents had adequate knowledge about thalassaemia.

Twenty two percent had another sibling with a similar disease. In $88 \%$ father was the breadwinner. Monthly income in $72 \%$ was less than 10,000 rupees. All said that they could not afford the expenses of travelling and investigations. Twenty two percent had no infusion pumps. Seventy five percent had satisfactory relationships with siblings and peers. In $74 \%$ teachers were happy about the school performance. Seventy two percent were interested in painting and music. Height was less than the $3^{\text {rd }}$ centile in $50 \%$. Thirty eight percent had altered facial appearance. (Other complications: 4\% had cardiomyopathy, $6 \%$ had diabetes, $6 \%$ had hypothyroidism). Eighty six percent had family support but none had adequate social support. Ninety eight percent of parents wanted to form a "thalassaemia support group".

\section{Discussion}

The chronically sick child and his family are likely to be affected psychologically. Anxiety about the illness may lead to restriction of some of the child's normal activities and prevent him from making friends. The parents' attitude may result in over-protective behaviour or in open rejection. The child's own feelings and reactions to his illness may affect his relationship with his siblings, with other adults, or with his parents ${ }^{3}$.

In our study majority (75\%) had satisfactory relationship with sibling and peers and $74 \%$ of children had impressed their teachers with regard to their school activities. Eighty percent of children had adequate family support despite the financial burden their parents had.

\section{Conclusions and recommendations}

- Eighty six percent had family support but none had adequate social support.

- Seventy five percent had satisfactory relationships with siblings and peers.

- Forming a "Thalassaemia support group" may help in providing social support.

\section{References}

1. Psychological support in thalassaemia (chapter 15, page 142), In 'Guidelines for the clinical management of thalassaemia', 2nd Edition, December 2007, Thalassaemia International Federation (TIF). Available from: www.thalassaemia.org.cy

2. Khurana A, Katyal S, Marwaha RK. Psychological burden in thalassaemia. Indian Journal of Pediatrics 2006; 73: 877 -80.

3. Tsiantis J, Xypolita-Tsantili D, PapadakouLagoyianni S. Family reactions and their management in a parents group with beta thalassaemia. Archives of Disease in Childhood, 1982; 57: 860-3. 